\title{
AVALIAÇÃO DA QUALIDADE DO EFLUENTE DE LAGOA DE ESTABILIZAÇÃO EM RELAÇÃO À RESOLUÇÃO CONAMA 430/2011: ESTUDO DE CASO DA ETE SANTA EUDÓXIA - SÃO CARLOS (SP).
}

\author{
Fernanda Igual Morales ${ }^{1}$
}

\author{
Erich Kellner ${ }^{2}$
}

João Sergio Cordeiro ${ }^{3}$

\begin{abstract}
RESUMO
Nos tratamentos de esgoto objetiva-se atender as legislações vigentes, em relação a determinados parâmetros físico-químicos, evitando prejuízo ao corpo receptor. As lagoas de estabilização de esgoto têm a função de reduzir a quantidade de matéria orgânica no tratamento de efluentes. Porém, esses ambientes são favoráveis à proliferação de cianobactérias potenciais produtoras de toxinas. Neste trabalho, as legislações CONAMA no 430/2011 e Decreto oㅜ 8468/76 para lançamento de efluentes foram utilizadas para a verificação da adequação ou não da ETE de Santa Eudóxia com os limites estabelecidos nas legislações citadas, alem da identificação dos gêneros de cianobactérias presentes no tratamento. Os parâmetros relacionados à padrões de emissão de efluentes foram analisados, assim como a proliferação de cianobactérias através de análise quantitativa e qualitativa. As coletas foram mensais e realizadas na junção da saída das lagoas facultativas de Julho de 2013 a Abril de 2014. Os parâmetros físico-químicos oxigênio dissolvido, $\mathrm{pH}$ e temperatura estão de acordo com as legislações, porém o efluente é potencialmente tóxico devido às cianobactérias presentes. $\mathrm{A}$ precipitação influenciou a diluição do nitrogênio total, porém não significativamente em relação à fósforo total.
\end{abstract}

PALAVRAS-CHAVE: Lagoas de estabilização; Legislação para emissão de efluentes; Cianotoxinas.

\footnotetext{
${ }^{1}$ Formada em Ciências Biológicas pela Universidade Federal de São Carlos. Mestranda no porgrama de Pós-Graduação em Engenharia Urbana na Universidade Federal de São Carlos. Email:

feigual@gmail.com.

${ }^{2}$ Doutor em Engenharia Hidráulica e Saneamento e professor na Universidade Federal de São Carlos. Email: erich.kellner@ufscar.br.

${ }^{3}$ Doutor em Engenharia Hidráulica e Saneamento e professor na Universidade Federal de São Carlos. Email: cordeiro@ufscar.br.
} 


\title{
QUALITY ASSESSMENT OF WASTE STABILIZATION POND IN RELATION TO RESOLUTION CONAMA 430/2011: CASE STUDY OF ETE SANTA EUDÓXIA - SÃO CARLOS (SP).
}

\begin{abstract}
In sewage treatment objective is to meet the current legislation in relation to certain physico-chemical parameters, avoiding injury to the receiving body. Stabilization ponds of sewage have the function of reducing the amount of organic matter in the wastewater treatment. However, these environments are favorable to the proliferation of cyanobacteria producing toxin. In this work, the laws CONAMA 430/2011 and Decree 8468/76 were used to check the suitability or not of ETE Santa Eudoxia with the limits in the legislation cited, besides the identification of cyanobacterial genera present treatment. Parameters related to the emission standards of effluent were analyzed, as well as the proliferation of cyanobacteria through quantitative and qualitative analysis. Sampling was performed monthly and at the junction of the output of facultative ponds July 2013 to April 2014. The physico-chemical parameters dissolved oxygen, $\mathrm{pH}$ and temperature are in accordance with the laws, but the effluent is potentially toxic due to cyanobacteria present The precipitation influenced the dilution of total nitrogen but not significantly to the total phosphorus.
\end{abstract}

KEYWORDS: Stabilization ponds; Legislation to effluent emissions; Cyanotoxins.

\section{EVALUACIÓN DE LA CALIDAD DE LA CHARCA DE ESTABILIZACIÓN DE RESIDUOS EN RELACIÓN A LA RESOLUCIÓN CONAMA 430/2011: ESTUDIO DE CASO DE ETE DE SANTA EUDOXIA - SÃO CARLOS (SP).}

\section{RESUMEN}

Em el tratamiento de aguas residuales el objetivo es cumplir la legislación vigente, en relación con determinados parámetros físico-químicos, evitando las lesiones en el cuerpo receptor. Las lagunas de estabilización de aguas residuales tiene la función de reducir la cantidad de materia orgánica en el tratamiento de aguas residuales. Sin embargo, estos ambientes son propicias para la proliferación de cianobacterias potenciales productoras de toxinas. En este trabajo, las leyes CONAMA 430/2011 y el Decreto 8468/76 para descarga de efluentes se utilizaron para comprobar la idoneidad o no de ETE de Santa Eudoxia con los límites establecidos en la legislación citada, además de la identificación de los géneros de cianobacterias presentes en tratamiento. Se analizaron los parámetros relacionados con las normas de emisión de efluentes, así como la proliferación de cianobacterias a través de análisis cuantitativo y cualitativo. El muestreo se llevó a cabo mensualmente y en el cruce de la salida de lagunas facultativas de Julio 2013 hasta abril 2014. Los parámetros físico-químicos de oxígeno disuelto, el pH y la temperatura son de conformidad con las leyes, pero el efluente es potencialmente 
Revista Nacional de

Gerenciamento de Cidades

tóxica debido a las cianobacterias presentes. Precipitaciones influyeron la dilución del nitrógeno total, pero no significativamente a la fósforo total.

PALABRAS CLAVE: Las lagunas de estabilización; La legislación para las emisiones de los efluentes; Cianotoxinas.

\section{INTRODUÇÃO}

Vários são os sistemas de tratamento de efluentes existentes no Brasil, cuja função é reduzir a quantidade de matéria orgânica no tratamento de efluentes. As lagoas de estabilização de esgoto são um tipo de tratamento presente em grande parte dos municípios pequenos e médios, existentes no país, além de apresentar satisfatório nível de tratamento principalmente em países tropicais pelo favorecimento do clima (GLOYNA, 1971; FURTADO et. al., 2009). Estas permitem uma maior rapidez das reações bioquímicas dos processos de digestão biológica da matéria orgânica, quando comparada com a ação natural do ambiente (OLIVEIRA, 2010).

Nessas lagoas de estabilização de esgoto pode ocorrer a presença de cianobactérias, que faz parte de todo o processo de degradação da matéria orgânica do esgoto. Grande quantidade de nutrientes pode resultar em um fenômeno conhecido como "Bloom" de cianobactérias, que se trata de uma alta densidade de algas e cianobactérias (FURTADO, et al., 2009). Essas cianobactérias se desenvolvem porque assimilam os nutrientes (nitrogênio e fósforo) e podem liberar cianotoxinas que são prejudiciais à saúde humana e animal. Em sistemas de tratamento, as águas com cianotoxinas podem ser relançadas em corpos d'água, prejudicando-os.

Nas lagoas facultativas (parte do sistema de lagoa de estabilização de esgoto) o processo biológico ocorre com a coexistência das cianobactérias e bactérias heterotróficas. O oxigênio liberado pelas cianobactérias através da fotossíntese é consumido pelas bactérias heterotróficas que degradam a matéria 
Revista Nacional de

Gerenciamento de Cidades

orgânica e estas por sua vez, liberam o gás carbônico que é utilizado pelas cianobactérias.

Calijuri, Alves e Dos Santos (2006) afirmam que as condições ambientais favoráveis às cianobactérias, são ambientes de água doce, $\mathrm{pH}$ de 6 a 9 e temperaturas variando entre 15 e $30^{\circ} \mathrm{C}$, com altas concentrações de nutrientes.

Os gêneros de cianobactérias potencialmente produtores de cianotoxinas são Anabaena, Aphanizomenon, Microcystis, Oscillatoria, Cylindrospermopsis, Radiocystis e Planktothrix (SIVONEN, JONES, 1999; CYBIS et. al., 2006; CETESB, 2006). Os gêneros de cianobactérias normalmente encontrados nas lagoas facultativas e de maturação são: Anabaena, Merispopedia, Microcystis, Oscillatoria, Spirulina, Synechococcus, Synechocystis (GLOYNA, 1971), (PEARSON et. al.; PEARSON \& SILVA; UEHARA \& VIDAL, citados por KELLNER; PIRES, 1998) ${ }^{4}$.

Von Sperling (1996) cita Oscillatoria, Phormidium, Anacystis e Anabaena como os principais gêneros de cianobactérias encontrados em lagoas de estabilização, coincidindo, em alguns gêneros, com os gêneros citados anteriormente. Microcystis ocorre em diversos ambientes.

Oliveira (2010) afirma que os sistemas de lagoas facultativas de estabilização de esgoto são ambientes favoráveis para a proliferação de cianobactérias, pois apresentam altas concentrações de nitrogênio e fósforo, além de pH normalmente acima de 8,0 e alta incidência de radiação solar.

No tratamento de esgoto objetiva-se atender as legislações vigentes para que não prejudique a qualidade do corpo receptor. Neste trabalho, duas legislações são utilizadas como base, CONAMA o 430/2011 e Decreto ㄲo 8468/76 (BRASIL 2011; SÃO PAULO, 1976). O Decreto em questão está relacionado tanto à padrões

\footnotetext{
${ }^{4}$ Pearson, H. W.; Mara, D.D.; Silva, S.A. (1998). Produção de oxigênio através da reação fotossintética de algas em diferentes sistemas de lagoas de estabilização no Nordeste do Brasil. In: Coleção de Trabalhos Técnicos Resultantes das Pesquisas Realizadas na EXTRABES: 1977-1983, Campina Grande - PB, UFPB/EXTRABES. 19 p. Pearson, H.W.; Silva, S.A. (1988). Variações Diurnas de Certos Parâmetros Físico-Químicos e Biológicos em Efluentes de Lagoas Facultativas e de Maturação. In: COLEÇÃO DE TRABALHOS TÉCNICOS RESULTANTES DAS PESQUISAS REALIZADAS NA EXTRABES 1977-1988., Campina Grande - PB, UFPB/EXTRABES. 19 p. Uehara, M.Y.; Vidal, W.L. (1989) Operação e manutenção de lagoas anaeróbias e facultativas. São Paulo, CETESB. (Série Manuais). 89 p.
} 
Revista Nacional de

Gerenciamento de Cidades

Tabela 1.2: Concentração de nitrogênio em esgotos domésticos brutos.

\begin{tabular}{cc}
$\begin{array}{c}\text { Concentrações de Nitrogênio em esgoto doméstico } \\
\text { bruto } \\
\text { Concentração (mg/L) }\end{array}$ \\
\hline Parâmetro & $35-60$ \\
Nitrogênio total & $20-35$ \\
Amônia & $0-1$ \\
Nitrato & \\
\hline
\end{tabular}

Fonte: Von Sperling (2005).

O mesmo autor cita valores para fósforo total que pode ser observado na Tabela 1.3.

Tabela 1.3: Concentração de nitrogênio em esgotos domésticos brutos.

\begin{tabular}{cc}
\hline $\begin{array}{c}\text { Concentrações de Fósforo em esgoto doméstico } \\
\text { bruto } \\
\text { Parâmetro }\end{array}$ & $\begin{array}{c}\text { Concentração (mg/L) } \\
\text { Fósforo Total }\end{array}$ \\
\hline Fósforo Orgânico & $1-5$ \\
Fosfatos & $3-7$ \\
\hline
\end{tabular}

Fonte: Von Sperling (2005).

Alguns parâmetros físico-químicos como $\mathrm{pH}$, temperatura e oxigênio dissolvido estão associados às legislações para lançamento de efluentes, enquanto que outros padrões como nitrogênio e fósforo também serão tratados neste trabalho por estarem relacionados com a proliferação de cianobactérias, mas não se referem à legislação.

Neste trabalho, o objetivo foi verificar os padrões de emissão de efluentes, presente nas legislações responsáveis com o que foi observado nas análises realizadas com o efluente do tratamento da ETE-Santa Eudóxia, São Carlos, SP, a fim de avaliar a adequação ou não com a legislação, além de identificar os gêneros de cianobactérias presentes no efluente e seu potencial tóxico. 
Revista Nacional de

Gerenciamento de Cidades

\subsection{Ponto de amostragem e freqüência das coletas}

As coletas foram realizadas uma vez por mês no ponto de junção das lagoas facultativas antes da saída para o rio. $O$ ponto em questão foi representado pelo código LF9 para melhor facilidade de identificação dos frascos de coleta. As coletas se iniciaram em Julho de 2013 e ocorreram até Abril de 2014, porém, os valores apresentados neste trabalho que são relacionados às cianobactérias, referem-se somente até o mês de Dezembro de 2013 por, até o momento, as análises seguintes ainda não terem sido realizadas.

Todas as coletas analisaram dados de Nitrogênio Total, Fósforo Total, Temperatura do meio líquido, $\mathrm{pH}$, e Oxigênio Dissolvido (OD), além de cianobactérias.

As análises de fósforo total e nitrogênio total foram realizadas seguindo o manual da Hach DR/2010 e através de kits e reagentes específicos para cada análise e lidos por meio do espectofotômetro Hach DR/2010. As análises ocorreram no Laboratório de Saneamento do Departamento de Engenharia Civil da Universidade Federal de São Carlos.

$\mathrm{O}$ oxigênio dissolvido, o $\mathrm{pH}$, e a temperatura da água foram medidos em campo através de oxímetro microprocessado modelo AT-160, phmetro de campo Instrutemp PHmeter PH-013M, termômetro acoplado no phmetro.

Em relação às cianobactérias, foram realizadas análises quantitativas através do método de Utermöhl com a técnica de sedimentação e contagem dos indivíduos (CALIJURI; ALVES; DOS SANTOS, 2006) e chaves de classificação e identificação de fitoplâncton até nível de gênero, enquanto que as análises qualitativas foram realizadas através de rede de plâncton com $20 \mu \mathrm{m}$ de abertura e as amostras foram armazenadas em frascos plásticos de capacidade de $200 \mathrm{~mL}$, porém somente $100 \mathrm{~mL}$ de amostra e o restante com formol a $4 \%$. A identificação também ocorreu por meio de bibliografia especializada.

Dados climatológicos como precipitação foram coletados através do INMET (BRASIL, 2014) para verificar a possível diluição dos nutrientes do meio. Esses 
西

Revista Nacional de

Gerenciamento de Cidades

dados se referem ao município de São Carlos e não especificamente do Distrito de Santa Eudóxia.

\section{RESULTADOS E DISCUSSÃO}

Primeiramente serão discutidos os dados referentes às legislações e em seguida os dados de cianobactérias, diluição do meio e nutrientes.

Em relação ao pH, é possível observar na Figura 3.1 que os valores obtidos nas coletas estiveram dentro dos padrões limite de ambas as legislações, e portanto, está adequado, indicando que este parâmetro não deve ser fator de prejuízo para a qualidade do rio que este efluente é desaguado. Pode-se considerar também que estes valores estão de acordo com o que foi afirmado por Calijuri, Alves e Dos Santos (2006) no que diz respeito ao pH ótimo entre 6 e 9 para desenvolvimento de cianobacérias e manutenção da vida aquática em geral. Além disso, pode-se verificar que o $\mathrm{pH}$ de maneira geral, esteve acima de 8,0, o que pode colaborar com a proliferação de cianobactérias assim com cita Oliveira (2010).

Figura 3.1: Valores de pH do pontos de coleta da lagoa e valores estipulados pelas Legislações.

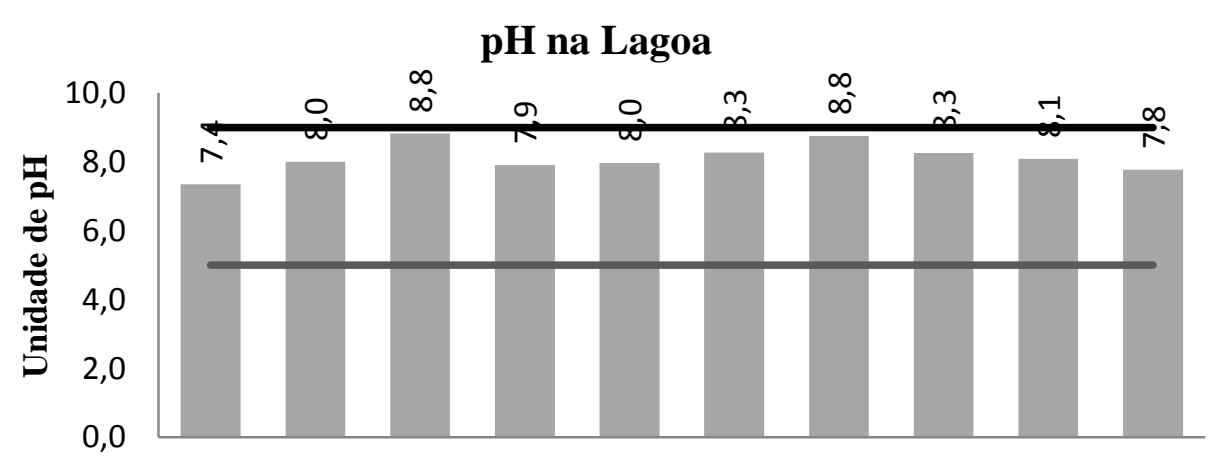

Jul 13 Ago 13 Set 13 Out 13 Nov 13 Dez 13 Jan 14 Fev 14 Mar 14 Abr 14

\section{Coletas}

pH na Lagoa

Limite mínimo estipulado pelas Legislações

Limite máximo estipulado pelas Legislações

Fonte: Do Autor. 
Revista Nacional de

Gerenciamento de Cidades

Em relação à temperatura do líquido da lagoa, pode se observar na Figura 3.2, que todas as análises atenderam ao valor limite estipulado por ambas as legislações assim como ocorreu com o pH, e dessa forma, podemos inferir que este também é um padrão que está de acordo e não prejudica o tratamento de esgoto e nem a qualidade do rio que receberá este efluente. O valor mais elevado em Janeiro de 2014, provavelmente apresenta essa característica devido à temperatura do ar nesse período, normalmente se apresentar elevada também, por ser uma época quente do ano.

É importante destacar também que, de maneira geral, a temperatura esteve dentro do limite entre 15 e $30^{\circ} \mathrm{C}$, afirmado por Calijuri, Alves e Dos Santos (2006) como importante para o desenvolvimento da vida aquática. Os meses de Dezembro de 2013 e Janeiro e Fevereiro de 2014, apresentaram valores maiores do que o valor de $30^{\circ} \mathrm{C}$, e isso também está relacionado com o período mais quente do ano, evidenciando que apesar de estar dentro da legislação, quando se trata da manutenção da vida aquática, isso pode ser prejudicial.

Figura 3.2: Temperaturas da água do ponto de coleta da saída da lagoa em cada coleta mensal de Setembro de 2013 a Janeiro de 2014.

\section{Temperatura na Lagoa}

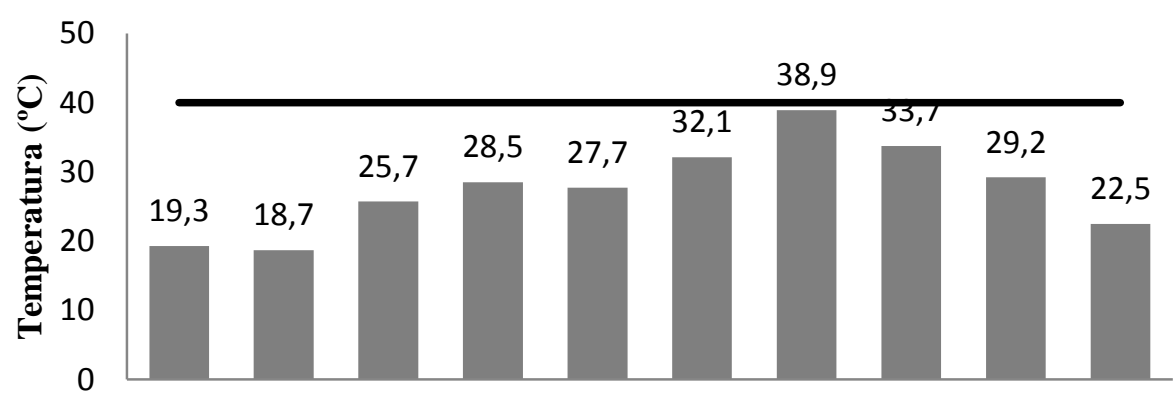

Jul 13 Ago 13 Set 13 Out 13 Nov 13 Dez 13 Jan 14 Fev 14 Mar 14 Abr 14

Coletas

Temperatura na Lagoa Limite estipulado pelas Legislações

Fonte: Do Autor. 
Revista Nacional de

Gerenciamento de Cidades

À respeito do OD, na Figura 3.3 é possível verificar que todas as análises apresentaram valores superiores ao limite mínimo de $5 \mathrm{mg} / \mathrm{L}$ e dessa forma, estão de acordo com o Decreto no 8468/76 para emissão de efluentes.

$\mathrm{Na}$ coleta de Agosto de 2013 o oxigênio dissolvido não foi registrado por problemas no equipamento.

Figura 3.3: Oxigênio dissolvido no no ponto da lagoa e limite estabelecido pela Legislação.

\section{Oxigênio Dissolvido na saída da Lagoa}

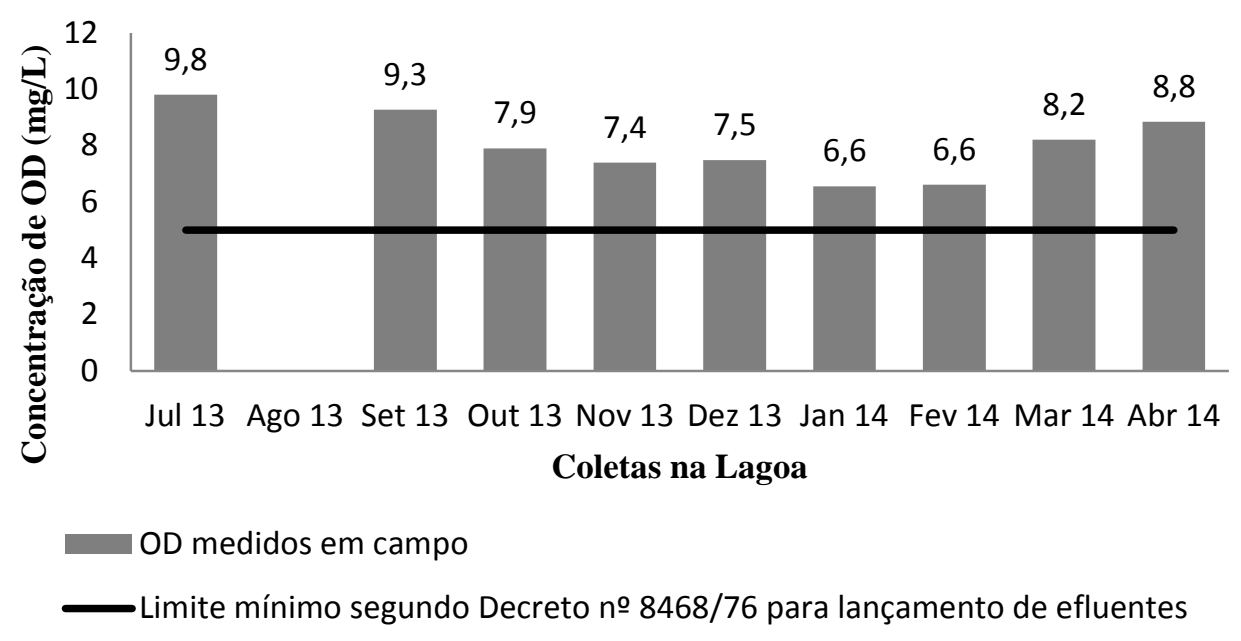

Fonte: Do Autor.

Os valores de nitrogênio total e fósforo total apresentados aqui serão discutidos com base na precipitação.

Como é possível observar na Figura 3.4, os valores de nitrogênio total obtidos nas análises, estiveram em geral, dentro do limite relatado por Von Sperling (2005) para esgoto bruto, apesar de neste trabalho tratar-se de esgoto após tratamento. O mês de Julho de 2013 apresentou valor mais elevado talvez pelo fato de não ter havido altas precipitações anteriormente à essa coleta. Também foram observados alguns valores abaixo do valor de 35 que deve ser por se tratar de efluente pós-tratamento, porém nada tão significativo como o valor da coleta de Julho de 2013. A média de concentração encontrada de nitrogênio total foi de 39 $\mathrm{mg} / \mathrm{L}$. 
Revista Nacional de

Gerenciamento de Cidades

Nesta mesma Figura é possível observar que em relação à diluição do corpo d'água demonstrado por Casali (2008), no mês de Dezembro de 2013 em que ocorreu a menor concentração de nitrogênio total, foi também um mês em que nos três dias anteriores à coleta, ocorreu a maior precipitação de todo o período de estudo (26,3 mm). No mês de Julho de 2013 em que ocorreu o maior valor de nitrogênio total do período estudado, a precipitação anterior aos dias de coleta foi de 3,8 $\mathrm{mm}$. Esse não foi o mês com a menor precipitação do período de estudo, evidenciando que a precipitação influencia, porém não é o único fator para uma menor ou maior concentração de nitrogênio total no meio.

Figura 3.4: Concentração de Nitrogênio Total no ponto de coleta da lagoa em todo o período de estudo.

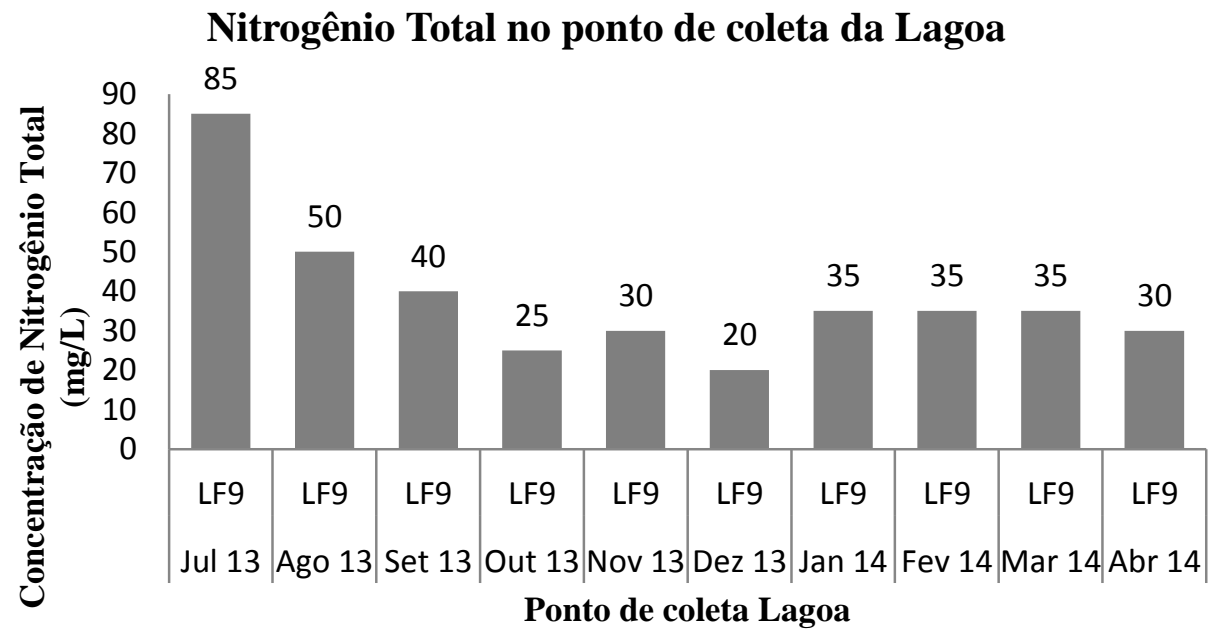

Fonte: Do Autor.

Em relação ao fósforo total, é possível observar na Figura 3.5 que todos os valores de concentração de fósforo total estiveram dentro dos limites de um esgoto bruto, indicados por Von Sperling (2005), apesar destes dados se referirem ao esgoto pós-tratamento. Em relação à diluição do meio citada por Casali (2008), quando referente à fósforo total, não houve grande relação da precipitação com a concentração do mesmo. 


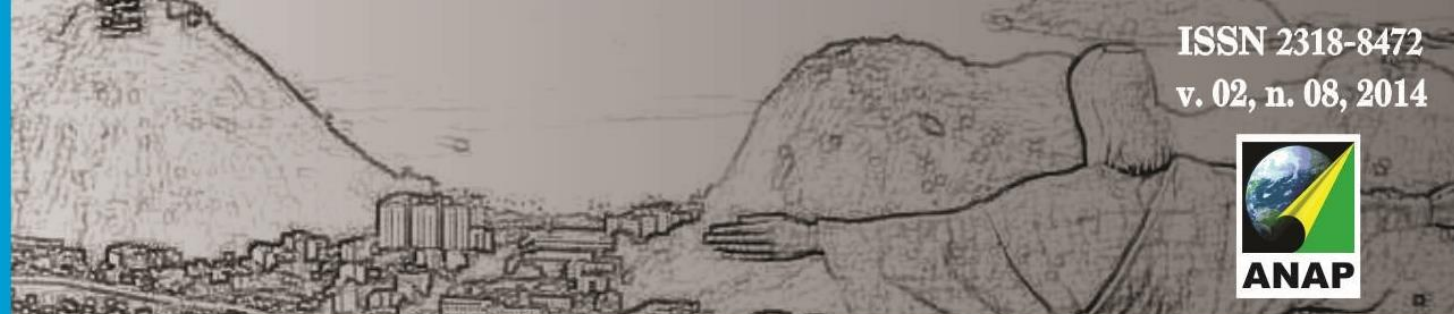

Revista Nacional de

Gerenciamento de Cidades

Figura 3.5: Concentração de Fósforo Total no ponto da lagoa em todo o período de estudo.

Fósforo Total no ponto de coleta da Lagoa

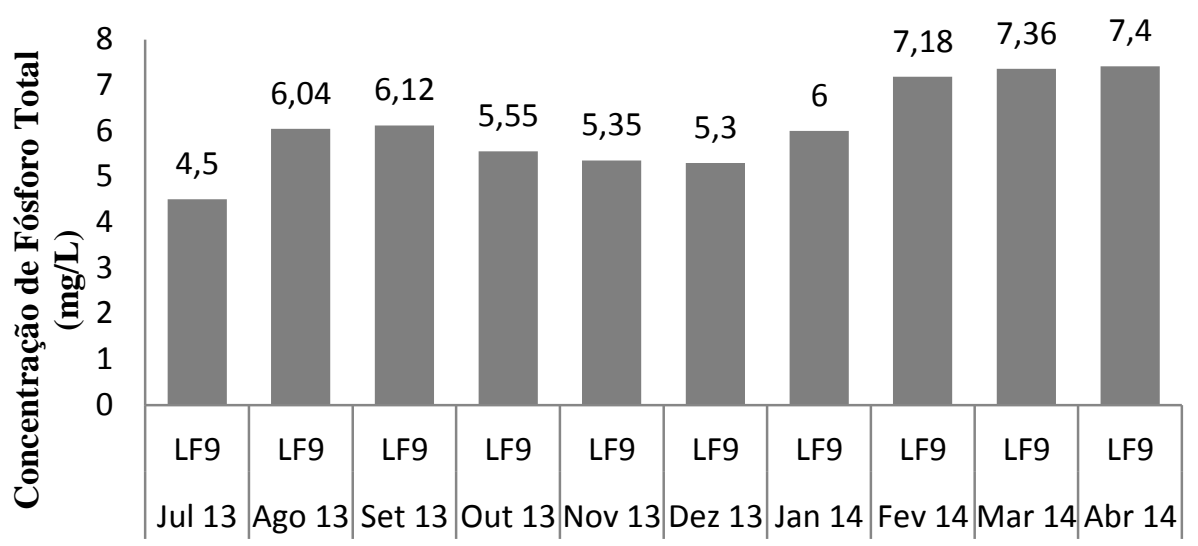

Ponto de coleta Lagoa

Fonte: Do Autor.

As principais características do esgoto pós-tratamento estão explicitadas na Tabela 3.1.

Tabela 3.1: Características das principais variáveis físico-químicas e biológicas do esgoto após tratamento (efluente da Lagoa).

\begin{tabular}{ccccc}
\hline Variáveis & Unidade & Média & Máximo & Mínimo \\
\hline Temperatura do efluente & $\circ \mathrm{C}$ & 27,6 & 38,9 & 18,7 \\
OD & $\mathrm{mg} / \mathrm{L}$ & 8 & 9,8 & 6,6 \\
Nitrogênio total & $\mathrm{mg} / \mathrm{L}$ & 39 & 85 & 20 \\
Fósforo total & $\mathrm{mg} / \mathrm{L}$ & 6 & 7,4 & 4,5 \\
$\mathrm{pH}$ & - & 8,3 & 8,8 & 7,9 \\
Cianobactérias & org./mL & 13858 & 55752 & 0 \\
\hline \multicolumn{5}{c}{ Fonte: do Autor. }
\end{tabular}

As variáveis bióticas deste trabalho correspondem à densidade de cianobactérias encontradas, observadas de maneira quantitativa e qualitativa.

Os três gêneros de cianobactérias mais significativos encontrados na saída da lagoa foram nessa ordem de densidade, Merismopedia, Pseudanabaena e Limnothrix. Porém todos os que estiveram presentes foram Limnothrix, Planktothrix, Pseudanabaena, células livres de Microcystis e Merismopedia. A presença de Microcystis e Merismopedia na lagoa é corroborada por autores como Gloyna (1971) 
Revista Nacional de

Gerenciamento de Cidades

e Pearson et. al.; Pearson \& Silva; Uehara \& Vidal (citados por KELLNER; PIRES, 1998), porém vai de encontro ao encontrado por Von Sperling (1996) que não indica nenhum dos gêneros encontrados no estudo dele com o que foi observado neste trabalho.

Das cianobactérias encontradas na lagoa de estudo, Planktothrix e Microcystis são consideradas produtoras de toxinas por Sivonen e Jones (1999).

\section{CONCLUSÃO}

Em relação aos padrões de $\mathrm{pH}$, temperatura e oxigênio dissolvido referentes às Legislações CONAMA o 430/11 e Decreto ํo 8468/76 para emissão de efluentes, todos eles estiveram de acordo, demonstrando uma adequação à legislação e dos valores ideais para a vida aquática.

Nitrogênio total apresentou uma relação com a diluição do meio quando em maiores precipitações, porém fósforo total não apresentou relação significativa. Ainda com relação à nitrogênio total, este esteve, de maneira geral, dentro do limite considerado normal para esgoto doméstico bruto. Fósforo total por sua vez, apresentou valores totalmente dentro dos valores considerados normais para o esgoto doméstico bruto.

À respeito das cianobactérias, os três principais gêneros encontrados durante o estudo foram Merismopedia, Pseudanabaena e Limnothrix. A presença de Merismopedia é considerada comum em lagoas facultativas. Dentre os gêneros encontrados, o destaque para Planktothrix e Microcystis se relacionam à produção de cianotoxinas, evidenciando efluente potencialmente tóxico, o que pode ser um problema para a qualidade do corpo d'água que recebe esse efluente.

Estudos futuros de monitoramento são necessários para controlar e analisar um possível impacto no corpo receptor. 


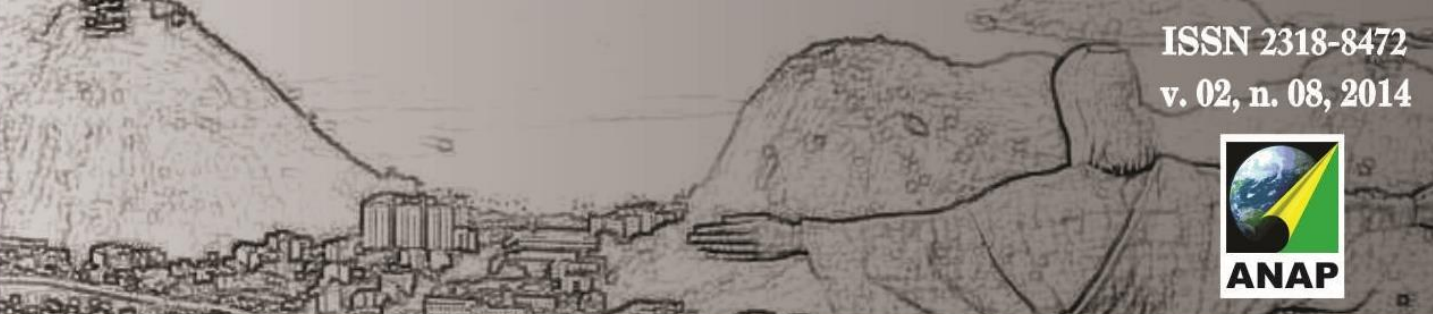

Revista Nacional de

Gerenciamento de Cidades

\section{REFERÊNCIAS}

BRASIL. Instituto Brasileiro de Geografia e Estatística. Censo Demográfico 2010. 2010.

BRASIL. Resolução CONAMA № 430 de 13 de maio de 2011. Dispõe sobre as condições e padrões de lançamento de efluentes, complementa e altera a Resolução oㅜ 357, de 17 de março de 2005, do Conselho Nacional do Meio Ambiente-CONAMA. Diário Oficial da União. Republica Federativa do Brasil, Poder Executivo, Brasília, DF, 16 mai. 2011.

BRASIL. Ministério da Agricultura, Pecuária e Abastecimento. Instituto Nacional de Meteorologia INMET. Disponível em: <http://www.inmet.gov.br/portal/index.php?r=bdmep/bdmep>. Acesso em: 14 jun. 2014.

CALIJURI, M. C.; ALVES, M. S. A.; DOS SANTOS, A. C. A. Cianobactérias e Cianotoxinas em Águas Continentais. São Carlos: Rima, 2006. 118 p.

CASALI, S. P. Variabilidade temporal da comunidade fitoplanctônica em lagoas facultativas de dois sistemas de tratamento de esgoto com diferentes configurações (Baixo Ribeira de Iguape, SP). 2008. 124p. Dissertação (Mestrado Programa de Pós-Graduação e Área de Concentração em Hidráulica e Saneamento) - Escola de Engenharia de São Carlos, Universidade de São Paulo, São Carlos, 2008.

CETESB. Dispõe sobre a homologação da revisão da Norma Técnica L5.303 - Fitoplâncton de Água Doce - Métodos Qualitativo e Quantitativo (Método de Ensaio) - dez/2005. 2006.

CYBIS, L. F. et. al. Programa de Pesquisa em Saneamento Básico PROSAB 4. Manual para Estudo de Cianobactérias Planctônicas em Mananciais de Abastecimento Público: Caso da Represa Lomba do Sabão e Lago Guaíba, Porto Alegre, Rio Grande do Sul. Rio de Janeiro: ABES, 2006. 64 p.

FURTADO, A. L. F. F. et al. Morphological and molecular characterization of cyanobacteria from a Brazilian facultative wastewater stabilization pond and evaluation of microcystin production. Hydrobiologia, São Carlos, 627, p. 195-209, 2009.

GLOYNA, E. F. Waste Stabilization Ponds. World Health Organization. Geneva, 1971.

KELLNER, E.; PIRES, E. C. Lagoas de estabilização: projeto e operação. Rio de Janeiro: ABES, 1998. $244 \mathrm{p}$.

OLIVEIRA, M. S. R. Avaliação da comunidade fitoplanctônica da lagoa facultativa do módulo III da estação de tratamento de esgoto de Mangabeira (João Pessoa - PB). 2010. 125 p. Dissertação de Mestrado. Escola de Engenharia de São Carlos, Universidade de São Paulo, São Carlos. 2010.

SÃO PAULO. Decreto n. 8.468, de 08 de Setembro de 1976. Aprova o Regulamento da Lei no 997, de 31 de maio de 1976, que dispõe sobre a prevenção e o controle da poluição do meio ambiente. Disponível em: <http://www.cetesb.sp.gov.br/Institucional/documentos/Dec8468.pdf>. Acesso em: 16 jun. 2014.

SIVONEM, K.; JONES, G. Cyanobacterial toxins. In: Chorus, I.; Bartram, J. (eds). Toxic Cyanobacteria in Water: A Guide to Their Public Health Consequences, Monitoring and Management. London. Cap.3, p. 41-111. 1999. 

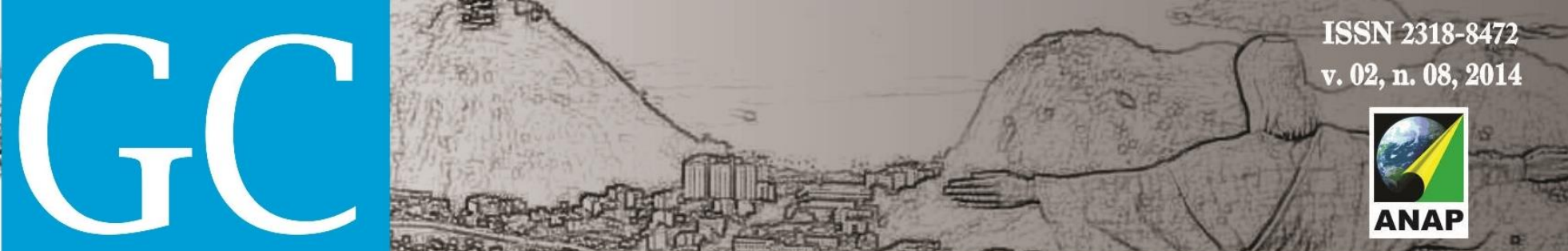

Revista Nacional de

Gerenciamento de Cidades

VON SPERLING, M. Princípios do Tratamento Biológico de Águas Residuárias: Lagoas de Estabilização. Belo Horizonte: Departamento de Engenharia Sanitária e Ambiental; Universidade Federal de Minas Gerais, 1996. Volume 3. 134 p.

VON SPERLING, M. Princípios do Tratamento Biológico de Águas Residuárias: Introdução à qualidade das águas e ao tratamento de esgotos. $3^{3}$ ed. Belo Horizonte: Departamento de Engenharia Sanitária e Ambiental; Universidade Federal de Minas Gerais, 2005. Volume 1. 452 p. 